\title{
Pragmatic Analysis of Verbal Humor in Friends-Based on Cooperative Principle
}

\author{
Jiaosheng Qiu \\ Taishan University, China
}

\begin{abstract}
This paper briefly introduces the main contents of Grice's cooperative principle of pragmatics and the connotation of the linguistic phenomenon of humour. Then, taking the popular sitcom Friends as an example, this paper lists the process of producing humor through deliberate violation of the cooperative principle in communication, so as to improve the readers' understanding of the generating mechanism of English humor and increase their interest in learning.
\end{abstract}

Index Terms — verbal humor, cooperative principle, pragmatic analysis

\section{INTRODUCTION}

\section{A. Cooperation Principle}

H.P. Grice(1975) formally put forward the Cooperative Principle (CP) in his book Logic and Conversation. Grice believed that in order to communicate effectively, speakers and listeners must cooperate with each other and abide by some principles. The principles that the two sides of the conversation abide by together are called the principle of cooperation(Li Lanping,2002).

1. The Maxim of Quantity

1) Make your contribution as informative as is required for the current purpose of the exchange, which means We should avoid inadequate information in an effective conversation.

2) Do not make your contribution more informative than is required, which means that we should also avoid redundant information in an effective conversation.

2. The Maxim of Quality(Try to make your contribution one that is true)

1) Do not say what you believe to be false.

2) Do not say that for which you lack adequate evidence.

3. The Maxim of Relation

What is said should be relevant to the content of the dialogue.

4. The Maxim of Manner, be perspicuous

a) Avoid obscurity;

b) Avoid ambiguity;

c) Be brief (avoid unnecessary prolixity);

d) Be orderly.

According to the principle of cooperation, the speaker and the hearer cooperate with each other tacitly and strictly abide by these principles is the prerequisite for the smooth development of language communication. However, in real life, the two sides of communication do not always abide by these principles. Even more often, they are more accustomed to violating the principle of cooperation intentionally or unintentionally. In this case, the hearer often understands an illocutionary meaning, or "special conversational meaning", through the literal meaning of the speaker's words. Humor often arises in this process(Wang Yanyan, 2009).

\section{B. Humor}

Humor can be divided into broad sense and narrow sense. It is often used in Western languages, including vulgar jokes... In a narrow sense, humor is different from cynicism, sarcasm and ridicule. These three four styles all contain the elements of laughter. However, laughter originally has different kinds of bitter laughter, wild laughter, light laughter and silly laughter, and different attitudes towards laughter. Some are hot and sour, some are gentle, some are contemptuous, some are sympathetic, some are phrases to explain the Yi, some are based on the whole outlook on life, there are ideological sustenance(Xu Han, 2011). The best humor, of course, is the expression of the brilliance of the soul and the richness of wisdom. Humor is the most emotional of all styles, which is a kind of wisdom that can arouse certain emotions in human psychology, and some kind of processing or destroying reality after proper control of logic. Humor or comedy has been promoted to the field of philosophy research. It is no exaggeration to say that humor is a philosophy(Liu Fuchang,1987).

According to Freud's theory, humor can express repressed thoughts in a socially permissible way. He points out that through humor, an individual can freely express his aggression (practical jokes) or sexual desire without fear of self-or 
superego-counterattack. In a joke, this energy is released in laughter because it is no longer needed to use the energy of anti-spiritual catharsis (Ouyang Yan, 2011).

\section{Friends}

The famous US TV series Friends is a world-renowned sitcom about the joys and sorrows of six friends in downtown apartment in New York over the past ten years. From 1994 to 2004, the series was updated at the rate of one season a year, with a total of 236 episodes in 10 seasons. Each season's ratings reached the top ten of the year. The actors won Emmy Awards for their roles on many occasions. The play was also rated as the most popular TV Series in history. The main characters in the play are: self-centered, simple-minded, from a charming wealthy woman to Rachel, Monica, a competitive and controlling perfectionist, Phoebe, an eccentric and uniquely minded environmentalist, Joey, a simple-minded, innocent playboy, and sensitive. Near neuroticism, humor is often used to cover up self-distrust in Chandler and over-serious, emotionally focused paleontology professor Ross.

\section{The AnAlysis of Humor in FriendS' Violation of CoOPERATIVE Principle}

As a classic American drama, many of the humorous passages in Friends just appear in violation of the politeness principle. We would like to take the first and second episodes of the first season as the material to show the readers how the characters in the play produce the humorous effect by violating the politeness principle.

\section{A. Violation of the Maxim of Quantity}

1. Inadequate Information

The lack of information in conversation leads to misunderstanding because of the inability to complete communication.

[Scene: After saying goodnight to each other, Monica went back to her room. Ross and Rachel were the only people in the living room.]

Ross: Mmm. (They both reach for the last cookie) Oh, no-

Rachel: Sorry-

Ross: No no no, go-

Rachel: No, you have it, really, I don't want it-

Ross: Split it?

Rachel: Okay.

Ross: Okay. (They split it.) You know you probably didn't know this, but back in high school, I had a, um, major crush on you.

Rachel: I knew.

Ross: You did! Oh.... I always figured you just thought I was Monica's geeky older brother.

Rachel: I did.

Ross: Oh. Listen, do you think- and try not to let my intense vulnerability become any kind of a factor here- but do you think it would be okay if I asked you out? Sometime? Maybe?

Rachel: Yeah, maybe...

Ross: Okay... okay, maybe I will...

Rachel: Goodnight.

Ross: Goodnight.

(Rachel goes into her room and Monica enters the living room as Ross is leaving.)

Monica: See ya.... Waitwait, what's with you?

Ross: I just grabbed a spoon. (Ross exits and Monica has no idea what that means.)

(Season 1, Episode 1)

After experiencing the divorce because his wife was a lesbian, Ross fell flat and lost hope in her emotional life. Rachel escaped from the wedding scene because of her sudden awakening. The two failed couples met in a cafe. Rachel was the object of Ross's secret love since high school. After everyone left, they talked about their former school in Monica's living room. Garden life, Rachel has always known Ross's feelings for her, Ross was very unexpected, rekindled the yearning for emotional life, and finally the courage to tentatively ask Rachel if she can ask her out, Rachel agrees cheerfully. Ross was very excited. When Monica came out and saw Ross excited and asked him what was wrong, he answered that she had just picked up a spoon. Obviously, Monica was puzzled by the spoon and didn't understand what Joy, who had a unique feeling for food, had said to Ross before. Ross provides a serious lack of information, the audience can see here, but can understand a smile, humor also produced.

2. Redundant Information

Like the lack of information, if too much information is provided in communication, it will also produce unexpected effects. There are many such situations in the play.

[Scene: Monica and Rachel's, everyone is sitting around the kitchen table. Rachel's credit cards are spread out on the table along with a pair of scissors.]

Rachel: Oh God, come on you guys, is this really necessary? I mean, I can stop charging anytime I want. 
Monica: C'mon, you can't live off your parents your whole life.

Rachel: I know that. That's why I was getting married.

Phoebe: Give her a break, it's hard being on your own for the first time.

Rachel: Thank you.

Phoebe: You're welcome. I remember when I first came to this city. I was fourteen. My mom had just killed herself and my step-dad was back in prison, and I got here, and I didn't know anybody. And I ended up living with this albino guy who was, like, cleaning windshields outside port authority, and then he killed himself, and then I found aromatherapy. So believe me, I know exactly how you feel.

(Pause)

(Season 1, Episode 1)

Rachel is a spoiled, wealthy woman and a real old-timer. After escaping from her wedding, she went to the Central Cafe to meet her old friend Monica. When she saw that everyone had their own work, she decided to live independently and not be old. However, it's easier said than done. After a frustration in finding a job, Rachel decisively went to buy several pairs of boots that were on sale. Under the pressure of friends, she admitted that she was still using her father's credit card. In order to get rid of the old hat, friends persuaded her to cut off all the credit cards her father had returned. Everyone was pressing. Rachel was very hesitant and felt it was difficult to ride a tiger. But Phoebe says, forgive her, it's the first time she's not independent. Rachel was grateful that someone had finally spoken for her. Thank Phoebe very much. Phoebe answered, "You're welcome. Everyone thinks the conversation should be over. But Phoebe continued to talk about her first trip to New York, from her mother's suicide to her stepfather's imprisonment, from her helplessness to her albino ex-boyfriend's suicide. Finally, she summed up how Rachel felt.

In this conversation, Rachel is in a pressing situation, just want someone to speak for her. As a result, the queer Phoebe talks a lot about his past behind Rachel's platform, which has nothing to do with Rachel's current situation. This strange behavior of Phoebe is the typical redundancy of information in the conversation, which means that Rachel and everyone are at a loss. After she finished, everyone paused. Of course, in the play, the humorous effect of this method is very obvious.

\section{B. Violation of the Maxim of Quality}

1. Deliberately stating what you believe to be wrong in communication

[Scene: Time Lapse, Ross has entered.]

Ross: (mortified) Hi.

Joey: This guy says hello, I wanna kill myself.

Monica: Are you okay, sweetie?

Ross: I just feel like someone reached down my throat, grabbed my small intestine, pulled it out of my mouth and tied it around my neck...

Chandler: Cookie?

Monica: (explaining to the others) Carol moved her stuff out today.

Joey: Ohh.

Monica: (to Ross) Let me get you some coffee.

Ross: Thanks.

Phoebe: Ooh! Oh! (She starts to pluck at the air just in front of Ross.)

Ross: No, no don't! Stop cleansing my aura! No, just leave my aura alone, okay?

Phoebe: Fine! Be murky!

Ross: I'll be fine, alright? Really, everyone. I hope she'll be very happy.

Monica: No you don't.

Ross: No I don't, to hell with her, she left me!

(Season 1, Episode 2)

Ross came to the cafe to say hello to everyone. Everyone saw that he was in a bad mood. Joey even joked that this guy greeted me in such a way that he wanted to commit suicide. Monica explained that it was because Ross's lesbian ex-wife took away her things this morning. Everyone sympathized with Ross, which made sensitive Ross very uncomfortable. Phoebe, in particular, even began to "clean up the ominous smell on Rose's head." Rose was annoyed and said, "I'll be fine, alright? Really, everyone. I hope she'll be very happy." The "I'll be fine" and "I hope she'll be very happy" here are obviously Rose's wrong words, their hearts are just the opposite, so when Monica pointed out "No you don't." He immediately changed his mouth to "No I don't, to hell with her, she left me!" Not only did he deny his previous blessing to his ex-wife, but he even began to curse her. The humorous effect of this place is very obvious, which shows Rose's frustration of betrayal by his wife appropriately. And not wanting to attract sympathy.

2. Deliberately saying inadequate evidence in communication

[Scene: Central Perk, Chandler, Joey, Phoebe, and Monica are there.]

Monica: There's nothing to tell! He's just some guy I work with!

Joey: Come on, you're going out with the guy! There's gotta be something wrong with him!

Chandler: All right Joey, be nice. So does he have a hump? A hump and a hairpiece?

Phoebe: Wait, does he eat chalk? 
(They all stare, bemused.)

Phoebe: Just, 'cause, I don't want her to go through what I went through with Carl- oh!

Monica: Okay, everybody relax. This is not even a date. It's just two people going out to dinner and- not having sex. Chandler: Sounds like a date to me.2.2 Criteria for Violations

(Season 1, Episode 1)

At the beginning of the sitcom Friends, Chandler, Phoebe and Joey pestered Monica to ask her about her latest date. Monica was reluctant to say more because she had no clear relationship, so they began to speculate without any evidence. Joey said directly, "Come on, you're going out with the guy!" There's gotta be something wrong with him." Chandler criticizes Joey's poisonous tongue and asks if he has a hump or hump and a hairpiece, while Phoebe's question is even stranger, asking if he can eat chalk. In the absence of meeting Monica's date at all, the three people made this unfounded assumption that it was a typical violation of the principle of cooperation. On the one hand, it was a kind joke between friends, on the other hand, it was to force Monica to tell more about him. In any case, the three people's practice achieved good humorous effect and aroused the audience. There were bursts of laughter.

\section{Violation of the Maxim of Relation}

Relevance principle refers to the fact that in communication, what is said should be related to the content of the communication, but not unrelated words. Otherwise, it will lead to poor communication or unexpected effects. Humor in many scenes in the play originates from the violation of this principle.

[Time Lapse, Ross has entered.]

Ross: (mortified) Hi.

Joey: This guy says hello, I wanna kill myself.

Monica: Are you okay, sweetie?

Ross: I just feel like someone reached down my throat, grabbed my small intestine, pulled it out of my mouth and tied it around my neck...

Chandler: Cookie?

Monica: (explaining to the others) Carol moved her stuff out today.

Joey: Ohh.

Monica: (to Ross) Let me get you some coffee.

Ross: Thanks.

Phoebe: Ooh! Oh! (She starts to pluck at the air just in front of Ross.)

Ross: No, no don't! Stop cleansing my aura! No, just leave my aura alone, okay?

Phoebe: Fine! Be murky!

Ross: I'll be fine, alright? Really, everyone. I hope she'll be very happy.

Monica: No you don't.

Ross: No I don't, to hell with her, she left me!

Joey: And you never knew she was a lesbian...

Ross: No!! Okay?! Why does everyone keep fixating on that? She didn't know, how should I know?

Chandler: Sometimes I wish I was a lesbian... (They all stare at him.) Did I say that out loud?

(Season 1, Episode 1)

This scene was mentioned earlier, when Rose was upset that his lesbian ex-wife had taken away her things. Everyone showed more or less sympathy for Rose. Phoebe even began to clean up the stench on Rose's head. Rose also had a little dispute with Phoebe. Rose also showed his true attitude towards his ex-wife, "to hell with her, she left me". At this time, Joey pranked Rose for not knowing that his wife was a lesbian. Rose was very angry and wronged. He said why people had to hold on to this problem. She didn't even know she was a lesbian at first. How could she know that she was a husband? At this point, whether you are sympathetic or ridiculous, you are talking about Rose and her ex-wife, and Chandler Stone's astonishing sentence "Sometimes I wish I was a lesbian" directly obscured all the people in the place, everyone stared at him. Obviously, on this occasion, Chandler's expression from the heart, no matter what the purpose is, is not appropriate. The audience also roared with laughter, indicating that Chandler's unreliable monologue had achieved excellent dramatic effect.

\section{Violation of the Maxim of Manner, Not Perspicuous}

\section{Obscurity}

[Scene Central Perk, everyone's there.]

Monica: What you guys don't understand is, for us, kissing is as important as any part of it.

Joey: Yeah, right!........'serious?

Phoebe: Oh, yeah!

Rachel: Everything you need to know is in that first kiss.

Monica: Absolutely.

Chandler: Yeah, I think for us, kissing is pretty much like an opening act, y'know? I mean it's like the stand-up comedian you have to sit through before Pink Floyd comes out.

Ross: Yeah, and-and it's not that we don't like the comedian, it's that-that... that's not why we bought the ticket. 
Chandler: The problem is, though, after the concert's over, no matter how great the show was, you girls are always looking for the comedian again, y'know? I mean, we're in the car, we're fighting traffic... basically just trying to stay awake.

Rachel: Yeah, well, word of advice: Bring back the comedian. Otherwise next time you're gonna find yourself sitting at home, listening to that album alone.

Joey: (pause)....Are we still talking about sex?

(Season 1, Episode 2)

In the Central Perk, they are talking about kissing. Ladies all agree that men don't understand the importance of kissing to women at all. Chandler makes a very vivid analogy. If you go to see the famous rock band Pink Floyd, the audience usually has to be patient to watch a talk show before they start performing, because it's a hot event, Ross said. People don't hate talk shows, but that's not why audiences buy tickets. Chandler then complained that girls would watch talk shows after the band ended, and Rachel told men very frankly that if they didn't want to listen to records at home later, they'd better let talk show actors on.

The conversation was wonderful because the metaphor was so appropriate that it caused applause from the audience, but it overlooked an important person who regarded food and sex as equally important Joey. Obviously, he didn't understand the metaphor. He paused for a moment and then asked "Are we still talking about sex". In Joey's opinion, their conversation is obviously obscure. Sex is sex. How can it be related to concerts and talk shows? In this scene, Joey's remark was the finishing touch and won the warmest applause.

2. Ambiguity

Rachel: (on phone) Daddy, I just... I can't marry him! I'm sorry. I just don't love him. Well, it matters to me! $\cdots$

Rachel: C'mon Daddy, listen to me! It's like, it's like, all of my life, everyone has always told me, 'You're a shoe! You're a shoe, you're a shoe, you're a shoe!'. And today I just stopped and I said, 'What if I don't wanna be a shoe? What if I wanna be a- a purse, y'know? Or a- or a hat! No, I'm not saying I want you to buy me a hat, I'm saying I am a ha- It's a metaphor, Daddy!

(Season 1, Episode 1)

After escaping, Rachel came to Monica's house and called her father to explain why she wanted to escape. She explained that she couldn't marry him because she didn't love him. Although we couldn't hear what his father said on the phone, we knew from Rachel's "it matters to me" that it didn't matter whether you loved Berry or not, but you had to marry him.

Then Rachel went on to explain that she made an analogy, like everyone always said Rachel was a pair of shoes, everyone thought so (Rachel himself recognized it), but suddenly one day, Rachel didn't want to be a shoe. What if she wanted to be a wallet? Or a hat? Obviously, the father on the other side of the phone didn't understand Rachel's meaning. As a wealthy doctor, the father should often use money to meet his daughter's requirements. He was also used to interpreting the words of his daughters as shopping hints. Rachel's sentence "I'm not saying I want you to buy me a hat, I'm saying I am a ha - It's a metaphor, Daddy" not only expresses Rachel's helplessness to his father, but also shows his previous life state, that is, constantly asking his father for money and selling what he likes. So Rachel's analogy made his father ambiguous and hit the audience's laughter point.

3. Unnecessary prolixity(not brief)

[Ross and Rachel go to hug but Ross's umbrella opens. He sits back down defeated again. A moment of silence follows as Rachel sits and the others expect her to explain.]

Monica: So you wanna tell us now, or are we waiting for four wet bridesmaids?

Rachel: Oh God... well, it started about a half hour before the wedding. I was in the room where we were keeping all the presents, and I was looking at this gravy boat. This really gorgeous Lamauge gravy boat. When all of a sudden- (to the waitress that brought her coffee) Sweet 'n' Lo?- I realized that I was more turned on by this gravy boat than by Barry! And then I got really freaked out, and that's when it hit me: how much Barry looks like Mr. Potato Head. Y'know, I mean, I always knew looked familiar, but... Anyway, I just had to get out of there, and I started wondering 'Why am I doing this, and who am I doing this for?'. (to Monica) So anyway I just didn't know where to go, and I know that you and I have kinda drifted apart, but you're the only person I knew who lived here in the city.

(Season 1, Episode 1)

Rachel, wearing a wedding dress, fled to the Central Cafe. She greeted everyone and fell silent. At Monica's urging, Rachel told everyone about the reason why she fled. In fact, Rachel realized before the wedding that she didn't love Barry. But because of the emotional excitement, Rachel's words are not concise, starting from the boat-shaped steamed meat dish in the gift room, talking about Berry's appearance and his sexual interest, and then saying that he was confused about why he wanted to get married, who I married for, and so on, which made the audience sound wordy but full of laughter. In fact, Rachel wanted to express that she had been living according to the wishes of her parents and friends, and had a successful marriage and birth, but suddenly realized at the wedding that she did not love Berry first, and then wanted to live her own life. That's why she ran away from marriage. Of course, we can also understand Rachel's meaning from her chattering narrative, but the language is too concise, violating the principle of cooperation, and generating humor. 


\section{Not Orderly}

[Scene: Monica and Rachel's, Chandler, Joey, Phoebe, and Monica are watching Three's Company.]

Monica: (taking a drink from Joey) Are you through with that?

Joey: Yeah, sorry, the swallowing slowed me down.

Monica: Whose little ball of paper is this?!

Chandler: Oh, uh, that would be mine. See, I wrote a note to myself, and then I realised I didn't need it, so I balled it up and... (sees that Monica is glaring at him) ...now I wish I was dead.

(Monica starts to fluff a pillow.)

Phoebe: She's already fluffed that pillow... Monica, you know, you've already fluffed that- (Monica glares at her.) -but, it's fine!

(Season 1, Episode 2)

Monica's mother is coming to the house. Monica is very nervous. She keeps cleaning up. She asks Joey if he's finished his drink, who throws the paper ball, and beats the pillow on the sofa. Everyone is frightened by her nervous look. Chandler, Joey and Phoebe are all incoherent in the order of speech in this conversation, which keeps the audience applauding. It also shows that Monica's relationship with her mother is somewhat tense and paves the way for her appearance. Although the actors were nervous, the scene was really funny to the audience.

\section{CONCLUSION}

Sitcom is a popular artistic form of expression, and verbal humor is its life. There are abundant literates on the theory of verbal humor, but few studies have been carried out from the perspective of pragmatics. From the perspective of pragmatics, this paper makes an analysis of the above humorous dialogues in the play, which helps us understand how the characters in the play produce humorous effects by violating the principle of cooperation, and also enables us to appreciate the film and television works better. At the same time, this paper further develops the study of humor mechanism within the framework of pragmatic theory, deepens the understanding of the internal mechanism of verbal humor, and verifies the cooperative principle, which will also benefit future English learning.

\section{REFERENCES}

[1] Grice, H.P. (1975). Logic and conversation. New York, Academic Press.

[2] Liu Fuchang. (1987). From the Cooperative Principle to See the Generation of English Humor. Modern Foreign Languages, 02, 32-36.

[3] Li Lanping. (2002). Pragmatic Principles and English Humor. Journal of Tianjin Institute of Foreign Studies, 03,23-28.

[4] Ouyang Yan. (2011). Discussing the relationship between cohesion and coherence based on discourse. Overseas English, 08, 268-269.

[5] Wang Yanyan. (2009). Pragmatic Analysis of Humorous Dialogue in Friends. Journal of Chifeng University (Chinese Philosophy and Social Sciences Edition), 08, 85-87.

[6] Xu Han. (2007). Pragmatic analysis of dialogues in American sitcom Friend]. Anhui Literature (second half month), 01, 39-40.

Jiaosheng Qiu was born in Tengzhou, China in 1983. He received his master's degree in foreign linguistics and applied linguistics from Shandong Agricultural University, China in 2012.

He is currently a lecturer in the Department of College Foreign Languages Teaching, Taishan University, Tai'an, China. His research interests include Second Language Acquisition and College English Teaching. 